Vol.01/ No. 02

Pages: $76-86$

https://www.irojournals.com/jucct/

DOI: https://doi.org/10.36548/jucct.2019.2.002

\title{
EFFICIENT ROUTING PROTOCOL WITH COLLISION AVOIDANCE IN VEHICULAR NETWORKS
}

\author{
Dr. D. Sivaganesan, \\ Professor, Department of Computer Engineering, \\ PSG Institute of Technology and Applied Research, \\ Coimbatore, India. \\ Email: sivaganesan@psgitech.ac.in
}

\begin{abstract}
The vehicle-Adhoc Networks are the specific type wireless adhoc networks, framed using the group of vehicles supporting the "on the fly' communication between vehicles on the roadside. This is basically developed to handle the traffic in an intelligent manner avoiding the unnecessary time elapse, discomfort and the fatalities during the travelling and in turn improvise the convenience in the transportation providing a continuous traffic movement. But certain emergent situations such as the natural disasters, accidents, damaged roads, sudden break down of the vehicles and the appearance of the emergency vehicles disturb the regular traffic flow and safety of the on road vehicles. To ensure the safety of on road vehicles and elude the collision of the vehicles that take place due to improper communications or communication attacks, the paper puts forth an effective routing protocol with collision avoidance, (ERPCA) to identify vehicles with the reliability to transfer information on time and evade the discomforts in travelling. The evaluation of the ERPCA with the network simulator-2 evinces the improvement in the performance of the vehicular-adhoc networks.
\end{abstract}

Keyword: Wireless Adhoc Network, Vehicular-Adhoc Network, Collision Avoidance, ERPCA, and Hybrid Routing

\section{INTRODUCTION}

Developing a smart city involves the improvements under many areas such as the development of smart homes, smart hospital, smart water system, electricity distribution etc. and smart transportation also takes an important role in turning the cities smart. The intelligent transportation system that remains as the back bone of the smart transportation is founded on the vehicular-adhoc networks [1-5]. The vehicular-adhoc network is a specific type of the wireless-adhoc network that enables the on road vehicles to communicate. This type of network, framed using the supporting vehicles is distributed in nature and has dynamic topologies. The vehicular-adhoc [6] mainly aims in supporting different type of applications such as warnings of traffic conditions, and information's such as parking availability, shortest route to destination, nearby stay available etc. [7-8].

ISSN: 2582-337X (online) 
Journal of Ubiquitous Computing and Communication Technologies (UCCT) (2019)

Vol.01/ No. 02

Pages: $76-86$

https://www.irojournals.com/jucct/

DOI: https://doi.org/10.36548/jucct.2019.2.002

The vehicular-network communicates in two ways either using the vehicle to vehicle communication and vehicle to road side unit communication [9]. The on board unit installed in the vehicles allows the vehicles to extend communication between vehicles and the road side units. The figure.1 below shows the vehicle to vehicle and the vehicle to infrastructure communication of the vehicular-adhoc network [10][11].

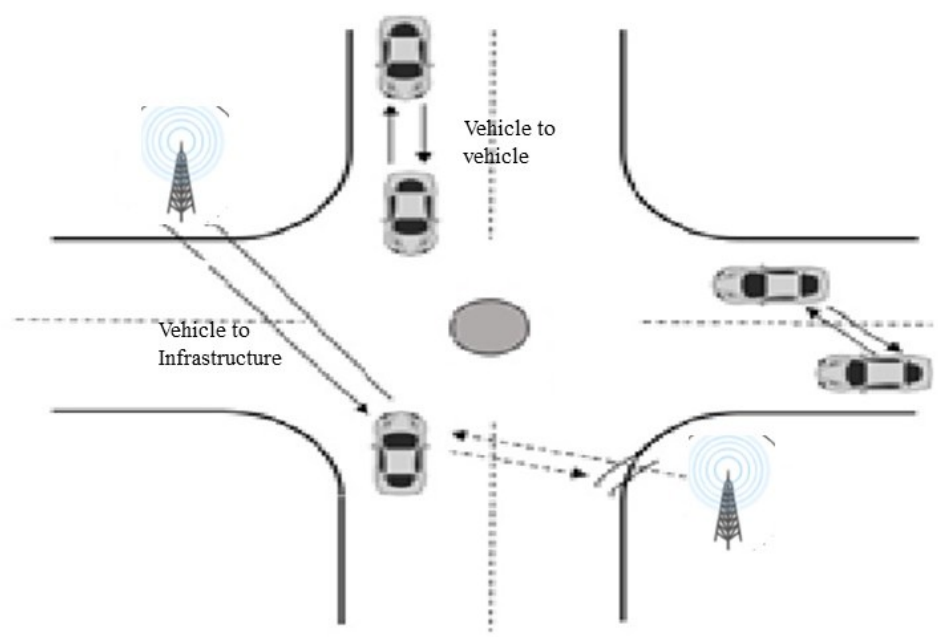

Fig.1 Vehicular Adhoc Network [1]

The vehicle either transmits or receives information using the vehicles or the road side units whichever is close by, the process of vehicle communication enables the vehicular-adhoc to experience various attributes such as the prediction concept, high mobility, geographical communication, changing frequencies and dynamic topologies. Due to its changing topologies and the high mobility routing becomes a very challenging task in the vehicular networks [12]. More over the routed information's are often affected by variety security threats affecting the communication. Further, certain emergent situations such as the natural disasters, accidents, damaged roads, sudden break down of the vehicles and the appearance of the emergency vehicles still worsen the traffic scenarios and disturbs the communication causing delay in the transmission or failure in transmission affecting the safety and the leading to fatalities on road.

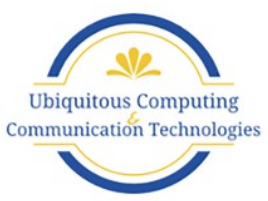


Journal of Ubiquitous Computing and Communication Technologies (UCCT) (2019)

Vol.01/ No. 02

Pages: $76-86$

https://www.irojournals.com/jucct/

DOI: https://doi.org/10.36548/jucct.2019.2.002

To ensure the safety of on road vehicles and elude the collision of the vehicles that take place due to improper communications or communication attacks, the paper puts forth an effective routing protocol with collision avoidance, (ERPCA) to identify vehicles with the reliability to transfer information on time and evade the discomforts in travelling. The paper is organized with the existing work in part 2, proposed work in part 3, result analysis in part 4 and conclusion in part 5

\section{EXISTING WORK [5]}

The existing vehicular network tries to enhance the security capabilities by developing a cloud-edge based roadside unit that is installed with an approximate member query filter to eliminate the request of the attack vehicles. The vehicles in the system is also aided with the on board unit that holds the approximate member query filter to be aware of the illegal access. This system allows the vehicles in the area to communicate only if its identity is revealed to the edge cloud. On revealing the identity of the vehicle receives a public key from the edge that is common for all the vehicles in the arena and verifies the key each time the information is conveyed. The vehicle that leaves the range is recorded in the database that maintains the entry and the exit list of the authorized vehicles. Though the existing the figure. 2 below shows the step in the existing methodology to have a communication between the vehicles and the edge model.

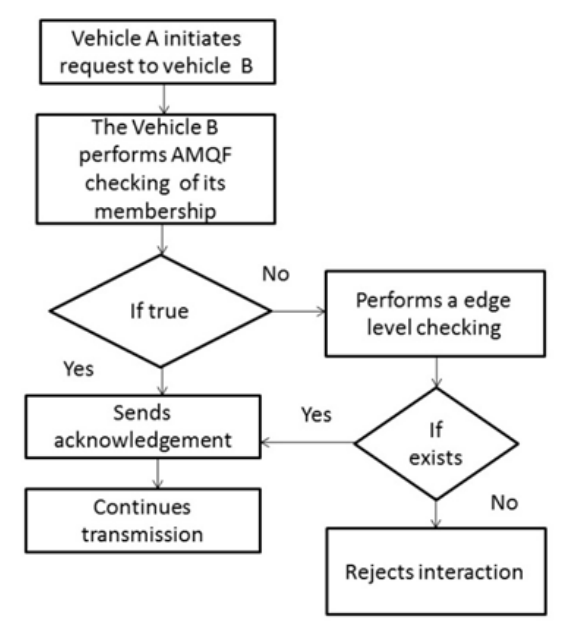

Fig.2 Existing VANET security [5]

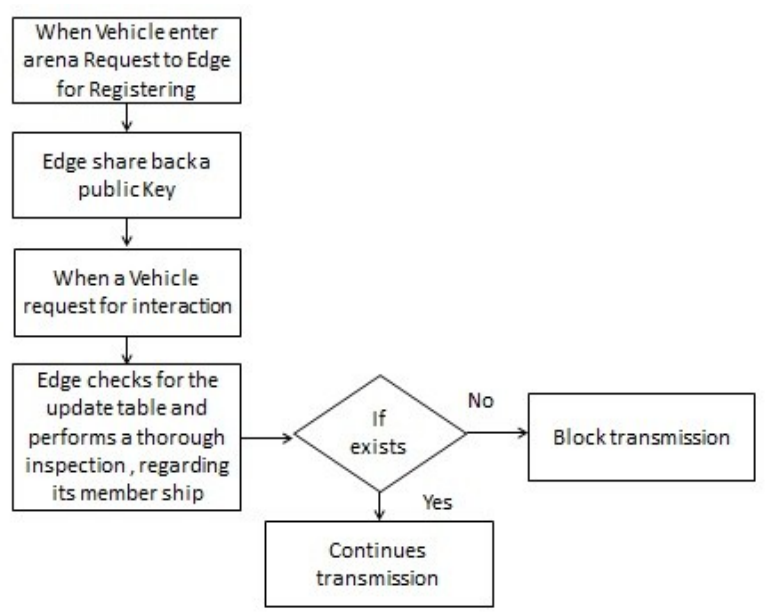

ISSN: 2582-337X (online) 
Journal of Ubiquitous Computing and Communication Technologies (UCCT) (2019)

Vol.01/ No. 02

Pages: 76-86

https://www.irojournals.com/jucct/

DOI: https://doi.org/10.36548/jucct.2019.2.002

Though very promising there are chances in which the even the attacking vehicles could reveal themselves as the normal vehicles and start communicating in the network affecting the actual communication and causing accidents and discomforts while travelling. This could further result in delay in the communication process affecting the throughput of the network and causing failure in information transmission.

\section{PROPOSED WORK}

The vehicular-adhoc network mainly scopes in improving the movement of the people and the goods. These networks obtain and procure an increasing attention due to the multitudes of the application supported by them. It provides the protection and convenience to the travelers and secures them from ill-fated incidents. The proposed process put forth in the paper aims at the improving the safety of the information transmitted on the emergent situations, by identify the reliable nodes with maximum residual energy. The flow chart below in fig. 3 expresses the phase in the proposed design. 
Journal of Ubiquitous Computing and Communication Technologies (UCCT) (2019)

Vol.01/ No. 02

Pages: 76-86

https://www.irojournals.com/jucct/

DOI: https://doi.org/10.36548/jucct.2019.2.002

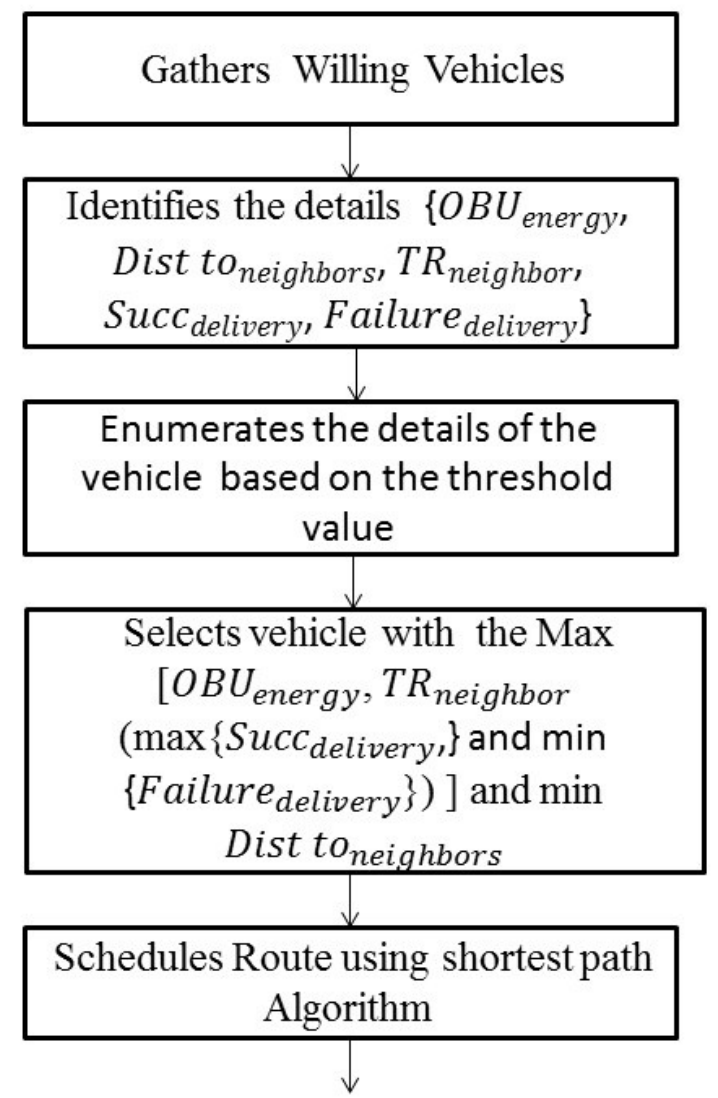

Transmits information

Fig.3 Proposed Flow Chart

The paper aims in improving the convenience in the transportation for the during the certain emergency situations such as the accidents, vehicle break down, natural disasters, damaged roads, appearance of the emergency vehicles etc.

For a set of vehicles $\left\{v_{1}, v_{2}, v_{3} \ldots \ldots \ldots \ldots v_{i}\right\}$ within the communication range $\left(C_{r}\right)$ of the road side unit $(R S U) /$ requesting vehicle $\left(\right.$ Rqst $\left._{\text {Vehicle }}\right)$, periodic request are sent by the road side unit or the vehicle. The sensor equipped in the vehicles in the on board units help in recognizing the request signal and responds back to it if it is willing to take part in the network, the willing ness of the vehicle is send back with the reply highlight the willingness as column in the reply as the ' 0 ' if not willing and ' 1 ' if willing. The Fig. 4 shows the request and the reply packet.

ISSN: 2582-337X (online)

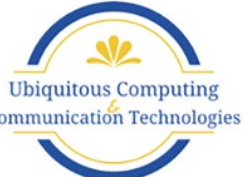


Journal of Ubiquitous Computing and Communication Technologies (UCCT) (2019)

Vol.01/ No. 02

Pages: $76-86$

https://www.irojournals.com/jucct/

DOI: https://doi.org/10.36548/jucct.2019.2.002

Request Packet

\begin{tabular}{|l|l|l|l|l|l|l|}
\hline Vehicle Id & Location & Speed & Direction & $\begin{array}{l}\text { Destination } \\
\text { id }\end{array}$ & Type & $\begin{array}{l}\text { Request of } \\
\text { Transmission }\end{array}$ \\
\hline
\end{tabular}

Reply Packet

\begin{tabular}{|l|l|l|l|l|l|}
\hline $\begin{array}{l}\text { Willi } \\
\text { ngnes } \\
\mathbf{s}=\mathbf{0}\end{array}$ & $\begin{array}{l}\text { Vehicles } \\
\text { id }\end{array}$ & Type & $O B U_{\text {energ? }}$ Dist to neighbor $_{\text {neighbo }}$ Succ $_{\text {delivery }}$ Failure $_{\text {delivery }}$ & \\
\hline
\end{tabular}

Information Blocked for the Requesting Vehicle

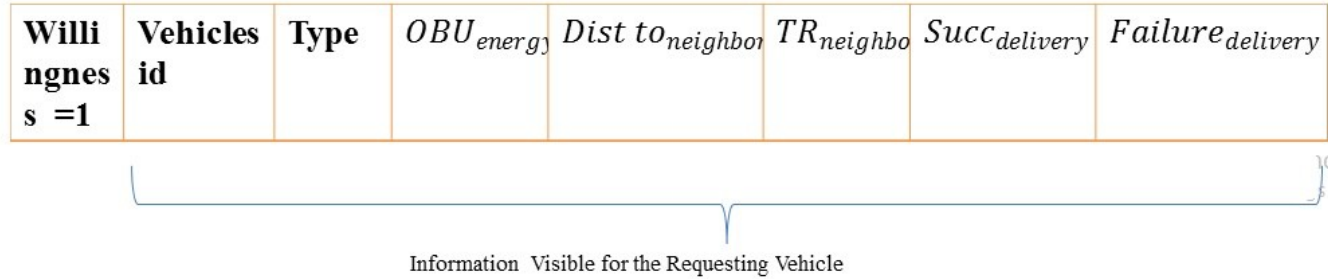

Fig.4Request and the Reply Packet

The road side unit/vehicle on receiving the reply checks it to know the willingness of the vehicle, the details \{energy the on board unit holds $\left(O B U_{\text {energy }}\right)$, the distance to its neighboring vehicles (Dist to neighbors $)$, the trust report from its neighbor $\left(T R_{\text {neighbor }}\right)$, details of number of data packets delivered safely $\left(S u c c_{\text {delivery }}\right)$ and the number of failures in the delivery $\left(\right.$ Failure $\left._{\text {delivery }}\right)$ ) of the willing vehicle is collected. The table.1 provides the threshold set for each parameter.

\begin{tabular}{|c|c|c|}
\hline$O B U_{\text {energy }}$ & Dist to neighbors & $T R_{\text {neighbor }}$ \\
\hline$>50 \%$ of original & $\begin{array}{c}<1 / 3 \text { of (source to } \\
\text { destination } \\
\text { distance) }\end{array}$ & $\begin{array}{c}\text { Success rate }=80 \% \\
\text { and above } \\
\text { Failure }<10 \%\end{array}$ \\
\hline
\end{tabular}

ISSN: 2582-337X (online)

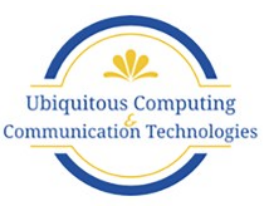


Journal of Ubiquitous Computing and Communication Technologies (UCCT) (2019)

Vol.01/ No. 02

Pages: 76-86

https://www.irojournals.com/jucct/

DOI: https://doi.org/10.36548/jucct.2019.2.002

Table.1 Threshold level

The parameter gathered is compared with the threshold level set, to identify the optimal vehicles for the communication. All the vehicles that show interest in joining the network are enumerated one by one to identify the optimal set of vehicles that are closer by to extend communication. The routes are identified using the shortest path algorithm (Dijkstra's Algorithm), that ensures the path framed between each vehicle form the source to the destination and the intermediate vehicles are short.

The information's from the source to the destination vehicle is transmitted safely without any attacks and failures through the shortest path. The information's of the vehicles as well as the shortest route are periodically updated to the server by regularly sending request and collecting the vehicle details; this avoids the link failures and protects the lifetime of the network as vehicles with the maximum on board unit energy and the trust are joined to the network and the one with lesser energy level and trust than the threshold level are rejected from becoming the members of the network.

\section{RESULT ANALYSIS}

The ERPCA model is evaluated in the network simulator-2, to verify the transmission rate, the total number of successful deliveries and the total number of failures in transmission and spot out the capabilities of the ERPCA. The output is verified for the varying trust percentage of the vehicles and compared with the prevailing method that provides the security assistance for the VANET using the cloud computing [5], the table.2 Shows the parameters used in the simulation.

ISSN: 2582-337X (online)

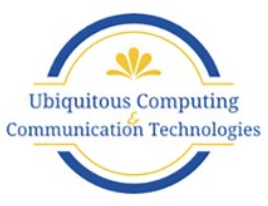


Journal of Ubiquitous Computing and Communication Technologies (UCCT) (2019)

Vol.01/ No. 02

Pages: $76-86$

https://www.irojournals.com/jucct/

DOI: https://doi.org/10.36548/jucct.2019.2.002

\begin{tabular}{|l|l|}
\hline \multicolumn{1}{|c|}{ Parameters } & \multicolumn{1}{c|}{ Values } \\
\hline Simulation Map & High ways \\
\hline Simulation seconds & 5000 seconds \\
\hline Area of simulation & $2500 * 30 \mathrm{~m}^{2}$ \\
\hline Speed of vehicles & $25-50$ \\
\hline Density of Vehicles & $100-1000$ \\
\hline Data packet size & $100-512$ bytes /packet \\
\hline Mobility model & Manhattan \\
\hline
\end{tabular}

Table.2 Simulation Parameters and Values

The fig. 5 below provides the results of the transmission rate observed for the ERPCA and the security assistance for the VANET using the cloud computing, the transmission rate of ERPCA is found to be high compared to the other method during the emergency situations on road and further improves the convince and the safety in the transmission.

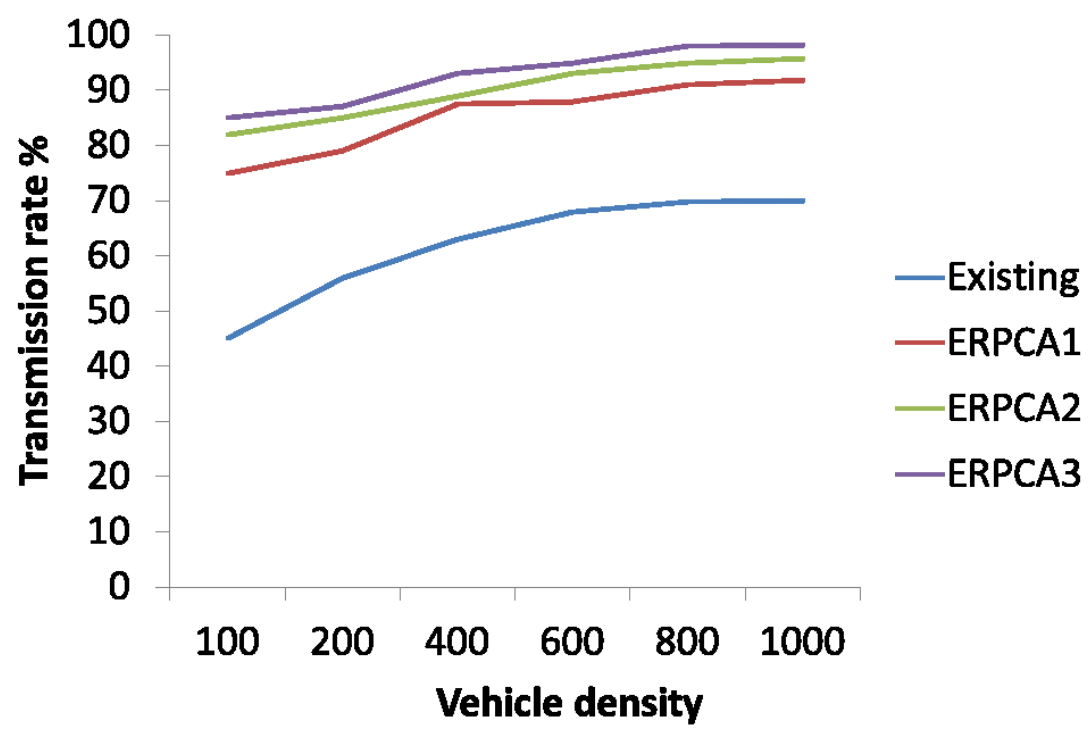

ISSN: 2582-337X (online)

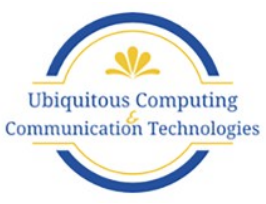


Journal of Ubiquitous Computing and Communication Technologies (UCCT) (2019)

Vol.01/ No. 02

Pages: $76-86$

https://www.irojournals.com/jucct/

DOI: https://doi.org/10.36548/jucct.2019.2.002

Fig.5 Transmission Rate

The fig. 6 below provides the number of successful deliveries and failures in the vehicular network by employing the ERPCA for varying trust percentage of the vehicles joined in the network.

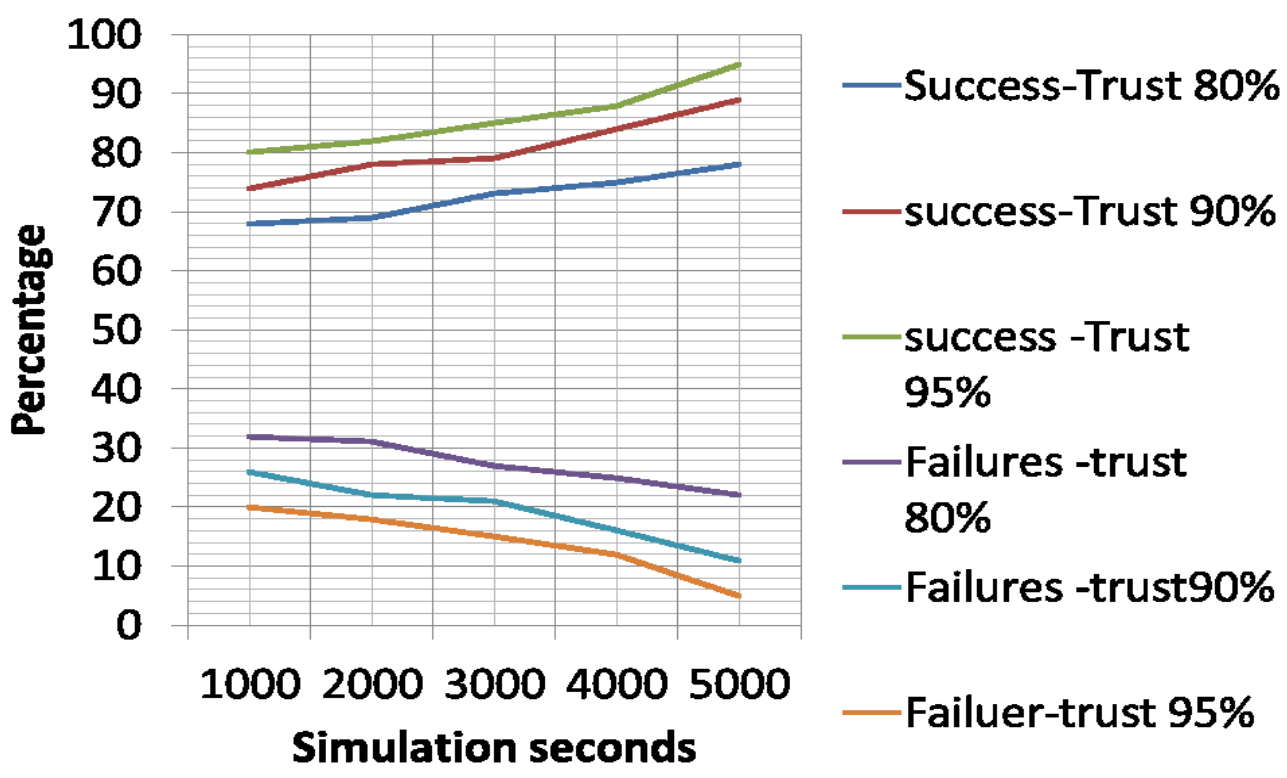

Fig.6 Successful deliveries and Failures Encountered by Employing ERPCA

The Table. 3 below provides the observed output for the varying trust percentage of the vehicles and its comparison with the prevailing method that provides the security assistance for the VANET using the cloud computing.

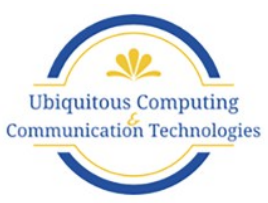


Journal of Ubiquitous Computing and Communication Technologies (UCCT) (2019)

Vol.01/ No. 02

Pages: 76-86

https://www.irojournals.com/jucct/

DOI: https://doi.org/10.36548/jucct.2019.2.002

\begin{tabular}{|c|c|c|c|c|c|c|c|c|c|c|c|c|}
\hline \multirow{2}{*}{$\begin{array}{l}\text { Vehicle } \\
\text { Density }\end{array}$} & \multicolumn{2}{|c|}{$\begin{array}{l}\text { Transmissi } \\
\text { on Rate \% }\end{array}$} & \multicolumn{2}{|c|}{$\begin{array}{c}\text { Successful } \\
\text { Deliveries } \\
\% \\
\end{array}$} & \multicolumn{2}{|c|}{$\begin{array}{c}\text { Failures in } \\
\text { deliveries } \\
\%\end{array}$} & \multicolumn{2}{|c|}{$\begin{array}{c}\text { Energy } \\
\text { consumpti } \\
\text { on (joules) }\end{array}$} & \multicolumn{2}{|c|}{ Delay (ms) } & \multicolumn{2}{|c|}{$\begin{array}{l}\text { Vehicles } \\
\text { affected \% }\end{array}$} \\
\hline & $\begin{array}{c}\text { ERP } \\
\text { CA }\end{array}$ & $\begin{array}{l}\text { EXI } \\
\text { STI } \\
\text { NG }\end{array}$ & $\begin{array}{c}\text { ERP } \\
\text { CA }\end{array}$ & $\begin{array}{l}\text { EXI } \\
\text { STI } \\
\text { NG }\end{array}$ & $\begin{array}{c}\text { ERP } \\
\text { CA }\end{array}$ & $\begin{array}{l}\text { EXI } \\
\text { STI } \\
\text { NG }\end{array}$ & $\begin{array}{c}\text { ERP } \\
\text { CA }\end{array}$ & $\begin{array}{l}\text { EXI } \\
\text { STI } \\
\text { NG }\end{array}$ & $\begin{array}{c}\text { ERP } \\
\text { CA }\end{array}$ & $\begin{array}{l}\text { EXI } \\
\text { STI } \\
\text { NG }\end{array}$ & $\begin{array}{c}\text { ERP } \\
\text { CA }\end{array}$ & $\begin{array}{l}\text { EXI } \\
\text { STI } \\
\text { NG }\end{array}$ \\
\hline 100 & 85 & 45 & 80 & 57 & 20 & 43 & 25 & 47 & $\begin{array}{c}.013 \\
4\end{array}$ & $\begin{array}{c}.123 \\
4\end{array}$ & 10 & 25 \\
\hline 200 & 87 & 56 & 82 & 59 & 18 & 41 & 34 & 56 & $\begin{array}{c}.014 \\
5\end{array}$ & $\begin{array}{c}.182 \\
3\end{array}$ & 7 & 45 \\
\hline 400 & 93 & 63 & 85 & 62 & 15 & 38 & 36 & 58 & $\begin{array}{c}.026 \\
7\end{array}$ & $\begin{array}{c}.234 \\
45\end{array}$ & 8 & 65 \\
\hline 600 & 95 & 68 & 88 & 67 & 12 & 33 & 45 & 64 & $\begin{array}{c}.034 \\
6\end{array}$ & $\begin{array}{c}.567 \\
8\end{array}$ & 4 & 78 \\
\hline 800 & 98 & 69.89 & 95 & 68 & 5 & 32 & 47 & 68 & $\begin{array}{c}.045 \\
67\end{array}$ & .678 & 5 & 95 \\
\hline 1000 & 98.2 & 70 & 98 & 74 & 2 & 26 & 50 & 75 & $\begin{array}{c}.056 \\
7\end{array}$ & $\begin{array}{c}.763 \\
2\end{array}$ & 3 & 100 \\
\hline
\end{tabular}

Table. 3 Comparison Table

\section{CONCLUSION}

The work carried out in the paper has successfully framed an efficient routing protocol with the collision avoidance to enhance the fluency in the traffic as well as convince in the travelling. The proposed methodology ensures the maximum successful deliveries of the information's from the source to the destination by identify the trusted vehicles with maximum energy level and minimum distance to the destination. This enables the vehicles to avoid getting piled up in the emergency situations on road. The ERPCA allows the safe and comfortable travelling, the results obtained based on the transmission rate, successful deliveries, failures, energy consumption and the delay in the transmission proves the capability of the proposed ERPCA and its comparison with the existing security assistance for the VANET using the cloud computing shows that the ERPCA has 20\% higher transmission rate compared to the prevailing method.

ISSN: 2582-337X (online)

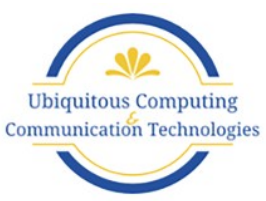


Journal of Ubiquitous Computing and Communication Technologies (UCCT) (2019)

Vol.01/ No. 02

Pages: $76-86$

https://www.irojournals.com/jucct/

DOI: https://doi.org/10.36548/jucct.2019.2.002

\section{References}

[1] Bhalaji, N. "PERFORMANCE EVALUATION OF FLYING WIRELESS NETWORK WITH VANET ROUTING PROTOCOL." Journal of ISMAC 1, no. 01 (2019): 56-71.

[2] Pandian, M. Durai. "ENHANCED NETWORK SELECTION AND HANDOVER SCHEMA FOR HETEROGENEOUS WIRELESS NETWORKS." Journal of ISMAC 1, no. 03 (2019): 160-171.

[3] Smys, S., and Jennifer S. Raj. "A STOCHASTIC MOBILE DATA TRAFFIC MODEL FOR VEHICULAR AD HOC NETWORKS." Journal of Ubiquitous Computing and Communication Technologies (UCCT) 1, no. 01 (2019): 55-63.

[4] Duraipandian, M. "PERFORMANCE EVALUATION OF ROUTING ALGORITHM FOR MANET BASED ON THE MACHINE LEARNING TECHNIQUES." Journal of trends in Computer Science and Smart technology (TCSST) 1, no. 01 (2019): 25-38.

[5] Neelaveni, R. "PERFORMANCE ENHANCEMENT AND SECURITY ASSISTANCE FOR VANET USING CLOUD COMPUTING." Journal of trends in Computer Science and Smart technology (TCSST) 1, no. 01 (2019): 39-50.

[6] Bhalaji, N. "QOS AND DEFENSE ENHANCEMENT USING BLOCK CHAIN FOR FLY WIRELESS NETWORKS." Journal of trends in Computer Science and Smart technology (TCSST) 1, no. 01 (2019): 1-13..

[7] Haoxiang, Wang, and S. Smys. "QOS ENHANCED ROUTING PROTOCOLS FOR VEHICULAR NETWORK USING SOFT COMPUTING TECHNIQUE." Journal of Soft Computing Paradigm (JSCP) 1, no. 02 (2019): 91-102.

[8] Koresh, Mr H. James Deva. "COMPUTER VISION BASED TRAFFIC SIGN SENSING FOR SMART TRANSPORT." Journal of Innovative Image Processing (JIIP) 1, no. 01 (2019): 11-19.

[9] Smys, S., Jennifer S. Raj, and Nixon Augustine. "AUTONOUMOUS VEHICLE NAVIGATION IN COMMUNICATION CHALLENGED ENVIRONMENTS-A SIMULATION APPROACH." (2011).

[10] Raj, Jennifer S., and A. Anto Prem Kumar. "ENERGY EFFICIENT LOCALIZATION AND ROUTING STRATEGY FOR CLUSTER BASED SENSOR NETWORKS."

[11] Ananthi, J. Vijitha, and Jennifer S. Raj. "A Peer to Peer Overlay Approach for Topology Maintenance in Wireless Networks."

[12] Smys, S., Hui-Ming Wee, and Meng Joo. "Introduction to the Special Section on Inventive Systems and Smart Cities." (2018): 32-33.

ISSN: 2582-337X (online)

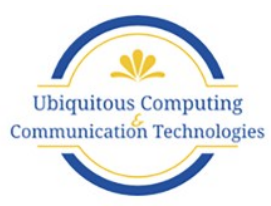

